\title{
Electrochemical study and applications of the selective electrodeposition of silver on quantum dots
}

\author{
Daniel Martín-Yerga*, Estefanía Costa Rama and Agustín Costa-García \\ Department of Physical and Analytical Chemistry, University of Oviedo, Julián Clavería 8, \\ 33006, Oviedo (Spain) \\ *Email: martindaniel@uniovi.es
}

\section{Contents}

S1. Fabrication of the $\mathrm{Ag} / \mathrm{AgCl}$ reference electrode

S2. Linear-sweep voltammetry experiments

S3. Confocal microscopy of the electrodeposition of Ag on QDs

S4. HRTEM and EDX analysis of Janus-like Ag-QDs nanoparticles

S5. Selectivity study towards the electrodeposition of other metals

S6. Scharifker-Hills model for nucleation studies

S7. Quantum dots detection procedure 


\section{$\underline{\text { S1. FABRICATION OF THE Ag/AgCl REFERENCE ELECTRODE }}$}

The lab-made $\mathrm{Ag} / \mathrm{AgCl}$ reference electrode was fabricated using a 10-100 $\mu \mathrm{L}$ micropipette tip as holder. The Ag wire (1mm, Alfa Aesar) is covered with $\mathrm{AgCl}$ by the application of $+0.8 \mathrm{~V}$ for $10 \mathrm{~min}$ in a solution of $1 \mathrm{M} \mathrm{KCl}$ (using another $\mathrm{Ag}$ wire as cathode). The salt bridge is generated following a modified procedure found in the literature[1] consisting of an agarose gel with $\mathrm{KNO}_{3} .0 .35 \mathrm{~g}$ of agarose is added to $25 \mathrm{~mL}$ of $0.5 \mathrm{M} \mathrm{KNO}_{3}$ solution and the mixture is heated and stirred to dissolve the agarose. The micropipette tip is placed in the solution (in a micro test tube), which is allowed to cool overnight to generate the agarose gel. Then, the tip is filled with saturated $\mathrm{KCl}$ and the $\mathrm{Ag} / \mathrm{AgCl}$ wire is placed in the solution. The reference electrode was connected to the potentiostat using alligator clips. The reference electrode was stored in a saturated $\mathrm{KCl}$ solution avoiding the light. The good reproducibility in the peak potentials of the voltammograms during the experiments (in different days) showed the good behaviour and stability of the fabricated reference electrode.

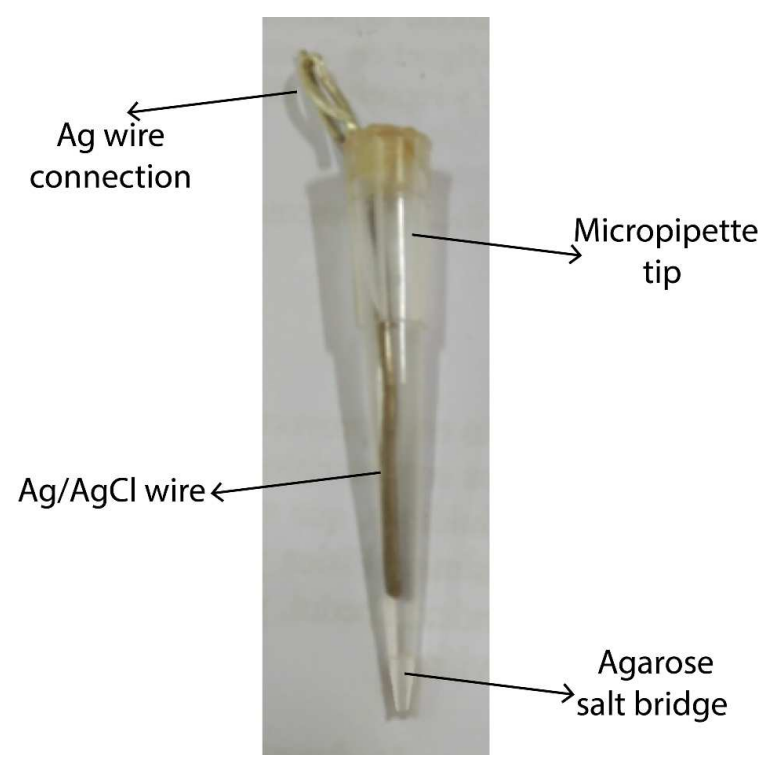

Figure S1. Lab-made $\mathrm{Ag} / \mathrm{AgCl}$ reference electrode in a micropipette tip. 


\section{S2. LINEAR-SWEEP VOLTAMMETRY EXPERIMENTS}

Firstly, the linear-sweep voltammetry (LSV) of the reduction/deposition was performed (Figure S2A). As shown in the figure, for an electrode without QDs, a single reduction process occurs at a potential about $-0.5 \mathrm{~V}$. This is the usual silver electrodeposition process on carbon surfaces. For a modified electrode, a new reduction process appears at a potential of $-0.05 \mathrm{~V}$. This process does not appear for bare carbon electrodes, or when the electrode was modified with QDs but the LSV was only performed with background electrolyte $\left(1 \mathrm{M} \mathrm{NH}_{3}\right)$. Therefore, this process involves silver and quantum dots, and it behaves very similar to the underpotential deposition of a metal on a metallic surface $[2,3]$. The reduction of silver in solution is enhanced by the presence of quantum dots in the electrode surface. QDs work as a catalyst for the silver reduction.

A)

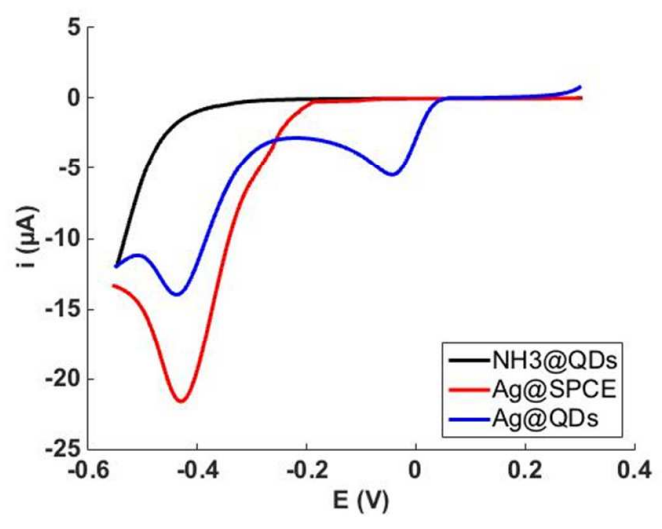

B)

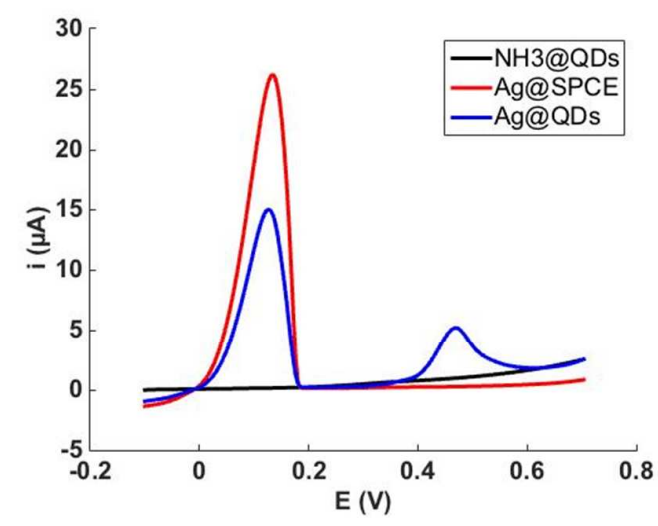

Figure S2. A) Linear sweep voltammetry from +0.3 to $-0.55 \mathrm{~V}$ for $\mathrm{NH}_{3}$ at a QDs-modified SPCE (black line), $250 \mu \mathrm{M}$ of silver at a SPCE (red line) and $250 \mu \mathrm{M}$ of silver at a QDsmodified SPCE (blue line). B) Linear sweep voltammetry from -0.1 to $+0.7 \mathrm{~V}$ for $\mathrm{NH}_{3}$ at a QDs-modified SPCE (black line), $250 \mu \mathrm{M}$ of silver at a SPCE (red line) and $250 \mu \mathrm{M}$ of silver at a QDs-modified SPCE (blue line) after electrodepositon applying $-0.2 \mathrm{~V}$ for $60 \mathrm{~s}$. 
On the other hand, a LSV study of the stripping processes after the electrodeposition by applying a potential of $-0.2 \mathrm{~V}$ for $60 \mathrm{~s}$ was carried out (Figure S2B). In the same way as for the reduction processes, significant differences were found. As shown in the figure, for a bare screen-printed carbon electrode, the typical stripping process of silver on carbon at about +0.05 V appeared. However, when QDs-modified electrodes are used, a new process at a more positive potential $(+0.45 \mathrm{~V})$ appeared. This process indicates a strong interaction of silver with the quantum dots, resulting in a more difficult stripping (higher energy stripping). This is significantly different from similar cases such as the electrodeposition of silver or copper on gold nanoparticles, as previously reported [4-6]. In such cases, only one stripping process appears, suggesting that the interaction of the deposited silver with quantum dots is much stronger than in gold nanoparticles.

\section{Limiting-control study}

A)

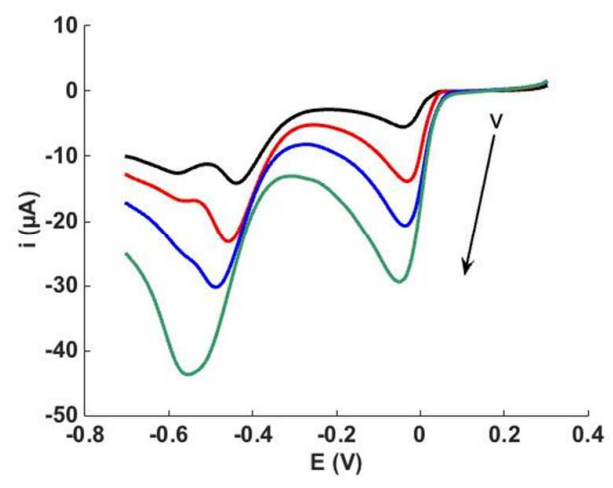

C)

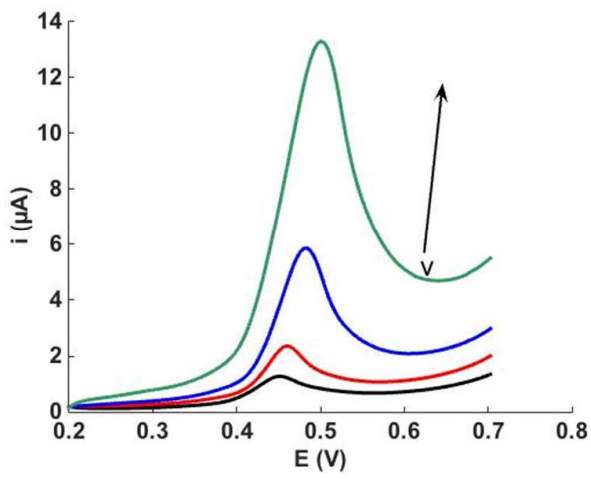

B)

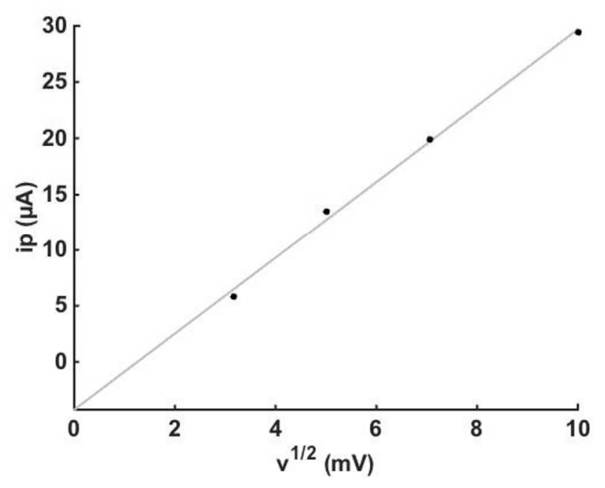

D)

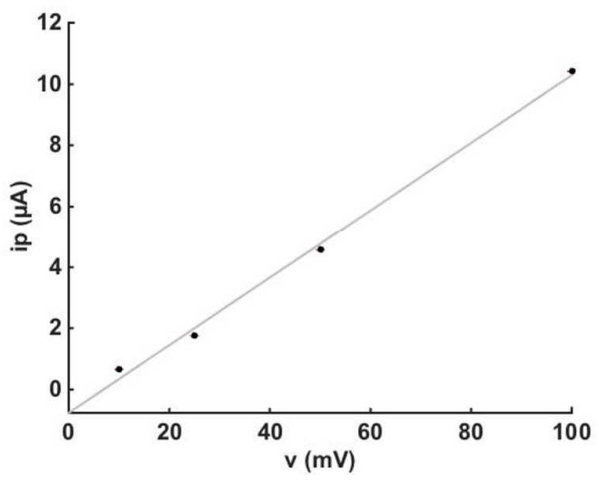


Figure S3. A) Linear sweep voltammetry from +0.25 to $-0.7 \mathrm{~V}$ of $250 \mu \mathrm{M}$ silver at different scan rates $(10,25,50,100 \mathrm{mV} / \mathrm{s})$ for a QDs-modified electrode. B) Relationship between the peak current of the peak at $-0.05 \mathrm{~V}$ and the square root of the scan rate. C) Linear sweep voltammetry from +0.2 to $+0.7 \mathrm{~V}$ of $50 \mu \mathrm{M}$ silver at different scan rates $(10,25,50,100 \mathrm{mV} / \mathrm{s})$ for a QDs-modified electrode after electrodeposition applying -0.1 V for $60 \mathrm{~s}$. D) Relationship between the peak current of the peak at $+0.45 \mathrm{~V}$ and the scan rate.

S3. CONFOCAL MICROSCOPY ANALYSIS OF THE ELECTRODEPOSITION OF SILVER $\underline{\text { ON QDs }}$

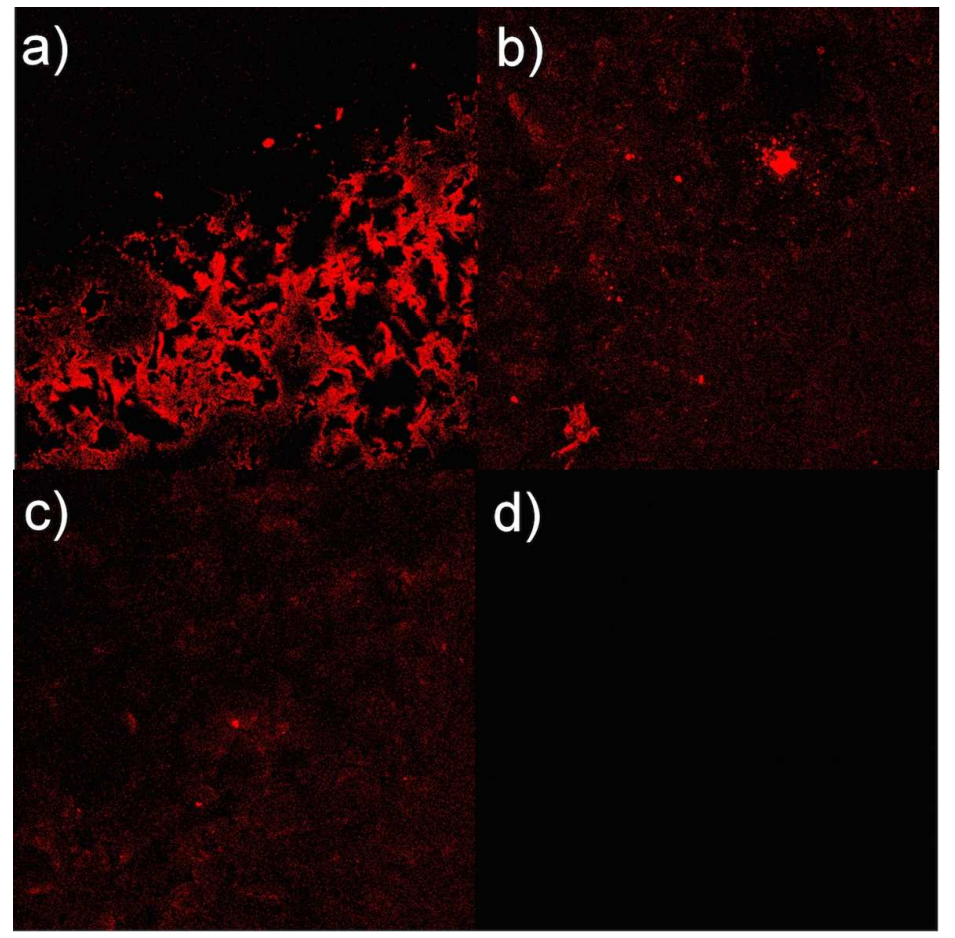

Figure S4. Confocal microscopy of a QDs-modified SPCE without silver electrodeposition (a) and after electrodeposition for 5 (b), 15 (c) and $30 \mathrm{~s}$ (d). 


\section{$\underline{\text { S4. HRTEM AND EDX ANALYSIS OF JANUS-LIKE Ag-QDs NANOPARTICLES }}$}

HRTEM imaging was performed on a carbon-coated TEM grid. This grid was modified with 2 $\mu \mathrm{L}$ of a $10 \mathrm{nM}$ solution of QDs until dryness. The electrodeposition was carried out in the grid in situ using a solution of $50 \mu \mathrm{M}$ of $\mathrm{Ag}$ (in $1 \mathrm{M} \mathrm{NH}_{3}$ ) applying $0 \mathrm{~V}$ for $1 \mathrm{~s}$. A grid modified with QDs (without electrodeposited Ag) was used for comparison. Metal electrodeposition on TEM grids have already been reported previously[7] and a similar system was used in our work. Briefly, the TEM grid was placed on a highly ordered pyrolytic graphite (HOPG; NT-MDT, ZYB quality) substrate with the carbon-coated side on top, The HOPG substrate was in contact with a gold-covered metallic sheet connected to the potentiostat. $5 \mu \mathrm{L}$ of the Ag solution was placed on the TEM grid, only making contact with the carbon membrane, which acts as a working electrode. A platinum wire, acting as auxiliary electrode, was coupled to the $\mathrm{Ag} / \mathrm{AgCl}$ reference electrode, previously described in section S1.

Quite different HRTEM images were obtained for the QDs-modified grid after the electrodeposition of silver. As mentioned in the main manuscript, a darker phase, attributed to polycrystalline silver, appears coating the QDs, as shown in Figure 3 of the main manuscript and in the Figure S5 (at a lower zoom resolution). In most of the nanoparticles, silver is preferentially localized on one side of the QDs, although in some cases silver is coating almost completely the QDs. This fact indicates that silver begin to grow preferentially in some location of the QD and then keep growing over all the nanoparticle. 


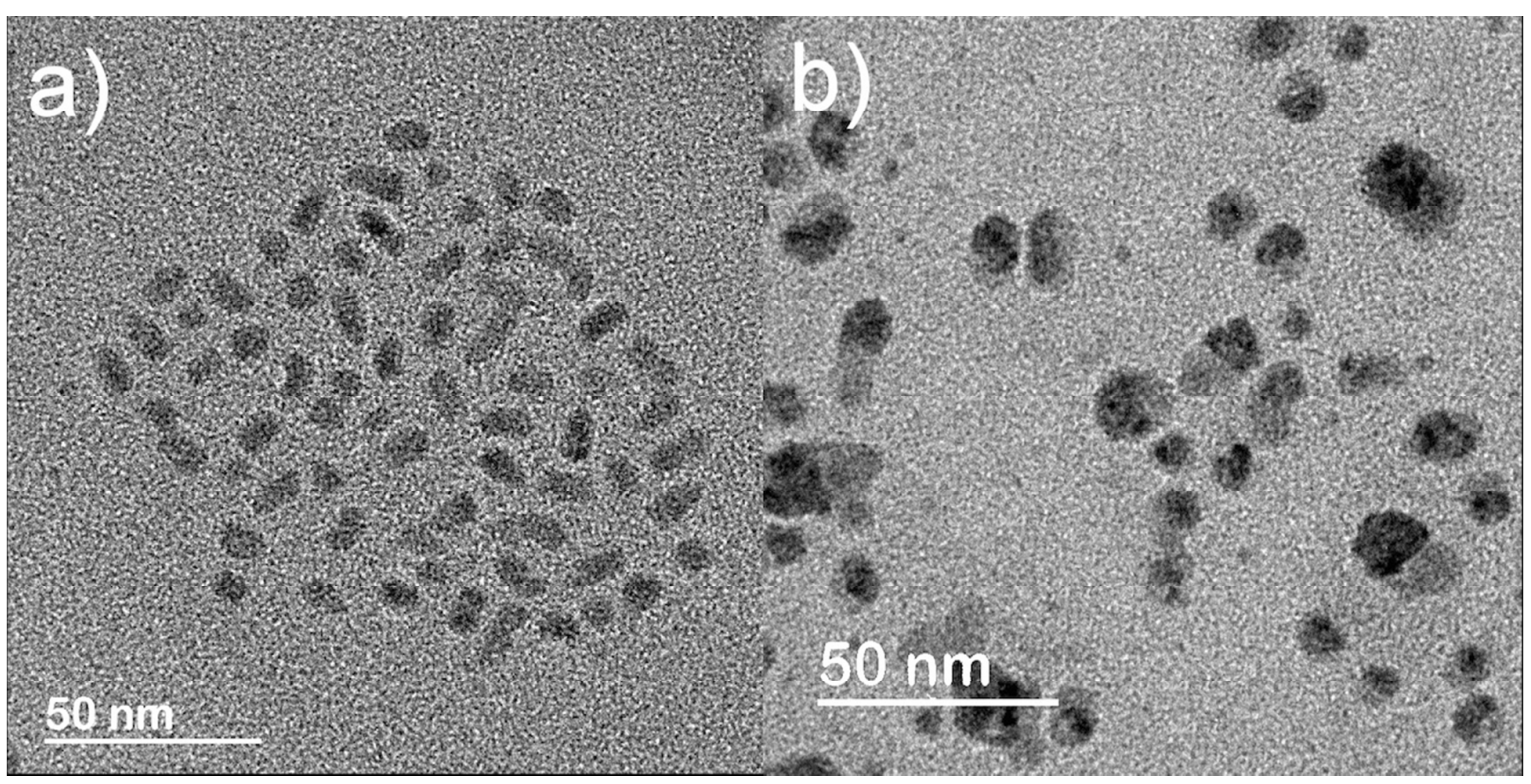

Figure S5. HRTEM images of the QDs nanoparticles (a) and Ag-QD Janus-like nanoparticles generated by the selective electrodeposition method (b).

Energy-dispersive X-ray spectroscopy (EDX) was carried out in the Scanning Transmission Electron Microscopy (STEM) mode in order to confirm the material of the different phases displayed in the obtained images. Although the STEM did not allow a resolution as high as HRTEM, a clear difference in the composition of the different phases was found, confirming that the darker phase was composed mainly of Ag coating the QDs (as the composition also showed $\mathrm{S}$ and $\mathrm{Se}$ in these areas). $\mathrm{S}$ and $\mathrm{Se}$ were used as elements to confirm the presence of QDs due to the interference between the $\mathrm{Cd}$ and $\mathrm{Ag}$ and $\mathrm{Zn}$ with $\mathrm{Cu}$ (main material of the grid). Figure S6 shows an EDX profile of the Janus-like particles. It can be seen as the Ag is preferably located in a side area of the QDs, whereas in the opposite area, although Ag is also detected, the contribution to the total composition is lower. 

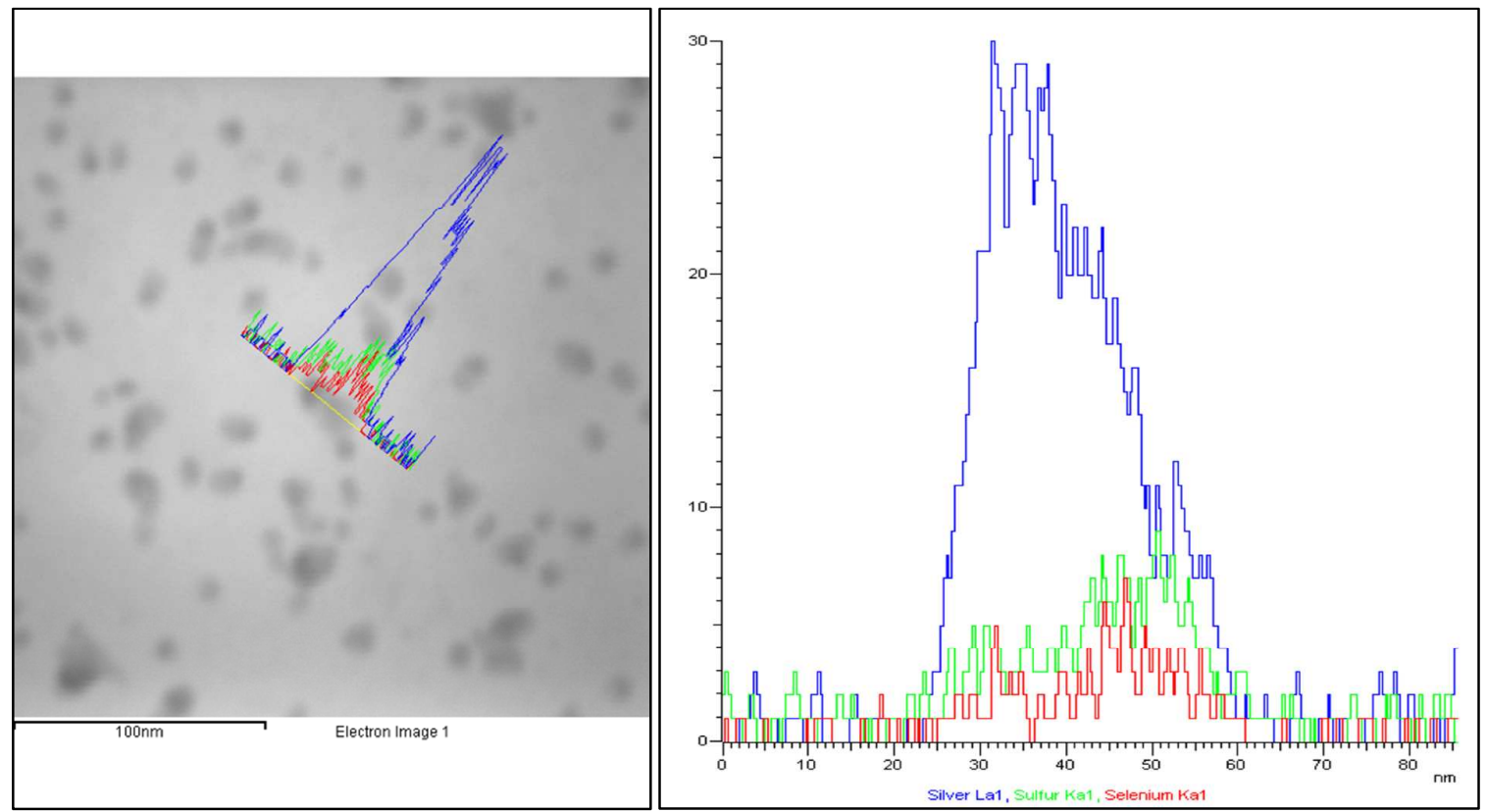

Figure S6. STEM image and composition profile (in atomic percentage) of the observed Januslike Ag-QD nanoparticles. Profile lines show the composition of silver (blue), sulfur (green) and selenium (red).

\section{S5. SELECTIVITY STUDY TOWARDS THE ELECTRODEPOSITION OF OTHER}

\section{METALS}

Cyclic voltammograms of $\mathrm{Co}(\mathrm{II}), \mathrm{Ni}(\mathrm{II})$ and $\mathrm{Cu}(\mathrm{II})$ at bare and QDs-modified screen-printed electrodes are shown in the Figure S7. $\mathrm{Zn}$ (II) was also tested but it did not show any process from $-1.3 \mathrm{~V}$ to $+0.8 \mathrm{~V}$ (data not shown). For Co(II), two cathodic processes are observed, the first wide peak attributed to the reduction of $\mathrm{O}_{2}$ (as stated in blank measurements (data not shown)), and a sharper peak at $-1.1 \mathrm{~V}$ attributed to the reduction of $\mathrm{Co}(\mathrm{II})$ to $\mathrm{Co}(0)$. Two anodic peaks are observed in the reverse wave, attributed to the oxidation of $\mathrm{Co}(0)$ to $\mathrm{Co}(\mathrm{II})$ and $\mathrm{Co}(\mathrm{II})$ to $\mathrm{Co}(\mathrm{III})$, respectively. For $\mathrm{Ni}(\mathrm{II})$, two cathodic processes are also observed, attributed to the reduction of $\mathrm{O}_{2}$ and a very small peak close to the hydrogen evolution attributed to the reduction 
of $\mathrm{Ni}(\mathrm{II})$ to $\mathrm{Ni}(0)$. In this case, one anodic peak is observed, attributed to $\mathrm{Ni}(0)$ to $\mathrm{Ni}(\mathrm{II})$ oxidation. It seems like some process is observed very close to the evolution of oxygen (as can be seen by the current increment), which could be attributed to the oxidation of $\mathrm{Ni}(\mathrm{II})$ to $\mathrm{Ni}(\mathrm{III})$, but it is not very well resolved to confirm it. However, no difference between the bare and QDsmodified electrodes was noticed for $\mathrm{Co}$ and $\mathrm{Ni}$.

$\mathrm{Cu}(\mathrm{II})$ voltammetry is an interesting case. Although, the same number of processes are observed at both electrodes, there are some differences in the potentials and peak currents. The cathodic processes can be attributed to the following reductions: $\mathrm{Cu}$ (II) to $\mathrm{Cu}$ (I) and $\mathrm{Cu}$ (I) to $\mathrm{Cu}(0)$ (probably coupled with oxygen reduction). At bare SPCEs, $\mathrm{Cu}(\mathrm{II})$ to $\mathrm{Cu}(\mathrm{I})$ is a quite wide process as it could be coupled to the oxygen reduction, and a small process attributed to $\mathrm{Cu}(\mathrm{I})$ to $\mathrm{Cu}(0)$ reduction can also be observed. At QDs-modified electrodes, the $\mathrm{Cu}(\mathrm{II})$ to $\mathrm{Cu}(\mathrm{I})$ reduction peak is sharper but with a lower peak current in comparison to bare electrodes, while the $\mathrm{Cu}(\mathrm{I})$ to $\mathrm{Cu}(0)$ process appears also sharper and higher in current. The first anodic process $(\mathrm{Cu}(0)$ to $\mathrm{Cu}(\mathrm{I}))$ seems quite similar in both electrodes except in the peak potential, which it has shifted to positive potentials at the SPCE electrode. However, the greater difference is noticed in the $\mathrm{Cu}(\mathrm{I})$ to $\mathrm{Cu}(\mathrm{II})$ oxidation. At bare electrodes, a very small process, almost totally inhibited, is observed at $-0.05 \mathrm{~V}$. This fact indicates that in this timescale very amount of $\mathrm{Cu}(\mathrm{I})$ is stable in the solution and is available for the oxidation. It has probably suffered disproportionation to $\mathrm{Cu}(\mathrm{II})$ and $\mathrm{Cu}(0)$, something similar can be seen in the cathodic wave (as the $\mathrm{Cu}(\mathrm{I})$ to $\mathrm{Cu}(0)$ is quite small). At QDs-modified electrodes a peak current 20 times higher is observed for the $\mathrm{Cu}(\mathrm{I})$ to $\mathrm{Cu}$ (II) oxidation. It seems that QDs are able to stabilize the $\mathrm{Cu}(\mathrm{I})$ ions, which then can be oxidized to $\mathrm{Cu}(\mathrm{II})$. 
However, even with the interesting behaviour of $\mathrm{Cu}(\mathrm{II})$ at QDs electrodes, it does not show a selective electrodeposition (catalytic reduction) or selective stripping (adsorption) in comparison to the bare electrode as have been displayed by silver.
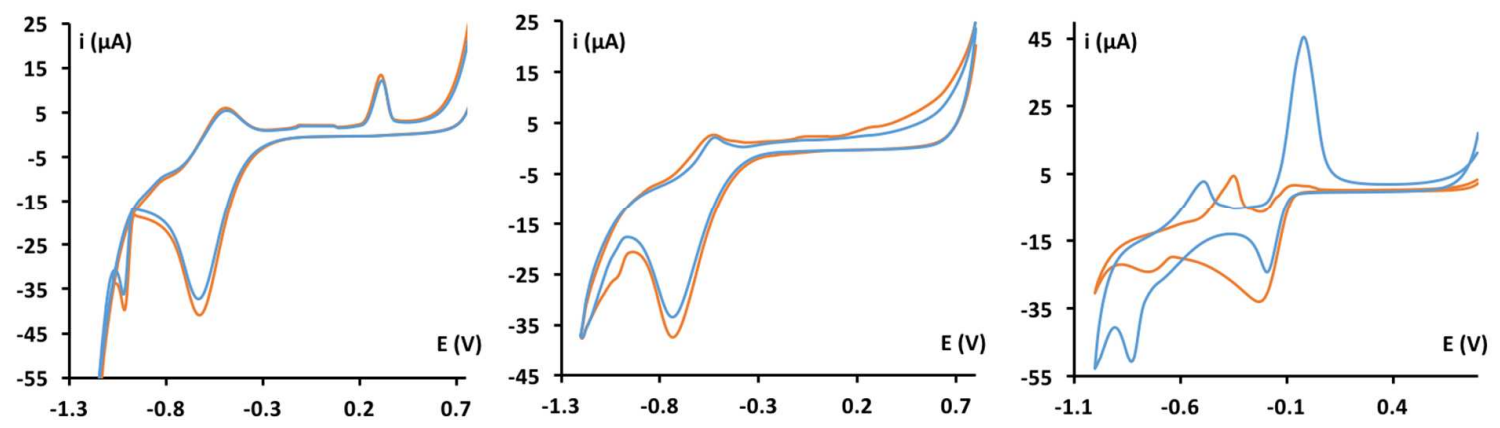

Figure S7. Cyclic voltammograms for $\mathrm{Co}(\mathrm{II}), \mathrm{Ni}(\mathrm{II})$ and $\mathrm{Cu}(\mathrm{II})$ on a bare screen-printed carbon electrode (orange line) and a QDs-modified screen-printed electrode (blue line).

\section{S6. SCHARIFKER-HILL MODEL FOR NUCLEATION STUDIES}

The nucleation and growth of the silver particles at bare screen-printed electrodes and modified with QDs was studied by analysing the current-time (i-t) transients in a chronoamperometric experiment. I-t transients were recorded in which the electrode potential was stepped from open circuit to different potentials $-0.2,-0.4,-0.5$ and $-0.6 \mathrm{~V}$. Electrode surface was previously modified with $10 \mu \mathrm{L}$ of a $10 \mathrm{nM}$ QDs solution.

I-t transients of the electrodeposition process were analysed following the Scharifker-Hills theoretical model [8]. In this model, there are two limiting nucleation mechanisms: instantaneous and progressive. The instantaneous nucleation corresponds to a slow growth of nuclei in a small number of active sites. The progressive nucleation corresponds to a fast growth of nuclei in many active sites.

The instantaneous nucleation in this model is described by the following equation:

$$
\left(\frac{i}{i_{m}}\right)^{2}=1.9542\left(\frac{t}{t_{m}}\right)^{-1}\left\{1-\exp \left[-1.2564\left(\frac{t}{t_{m}}\right)\right]\right\}^{2} \text { (S1) }
$$


where $i$ is the current density, $i_{m}$ is the maximum current density, $t$ is time and $t_{m}$ is the time at the maximum current.

The progressive nucleation can be expressed by the following equation:

$$
\left(\frac{i}{i_{m}}\right)^{2}=1.2254\left(\frac{t}{t_{m}}\right)^{-1}\left\{1-\exp \left[-2.3367\left(\frac{t}{t_{m}}\right)\right]\right\}^{2} \text { (S2) }
$$

The experimental i-t transients were analysed with these expressions using the experimental obtained values for imax and tmax.

An expression to estimate the nuclei population density was also predicted for this model:

$$
N_{0}=0.065\left(\frac{1}{8 \pi C_{0} V_{m}}\right)^{1 / 2}\left(\frac{n F C_{0}}{i_{m} t_{m}}\right)^{1 / 2}
$$

where $\mathrm{n}$ is the number of electrons involved, $\mathrm{F}$ is the Faraday constant, $\mathrm{C}_{0}$ is the concentration of species in bulk and $\mathrm{V}_{\mathrm{m}}$ is the molar volume. Table $\mathrm{S} 1$ shows the estimated silver nuclei population densities deposited at $-0.2 \mathrm{~V}$ for bare SPCEs and QDs-modified electrodes using a $250 \mu \mathrm{M}$ silver solution. In good agreement with the theoretical model a greater number of active sites are calculated for a progressive nucleation as the produced at QDs-modified electrodes.

\begin{tabular}{ccc}
\hline & $\mathbf{- 0 . 2}$ V SPCE & -0.2 V QDs \\
\hline $\mathrm{N}_{\mathbf{0}}\left(\right.$ particles $\left./ \mathrm{cm}^{2}\right)$ & $3.8 \times 10^{5}$ & $8.1 \times 10^{8}$
\end{tabular}

Table S1. Estimated nuclei population densities deposited at $-0.2 \mathrm{~V}$ for bare SPCEs and QDs-modified electrodes using a $250 \mu \mathrm{M}$ silver solution.

As the stripping process is controlled by the adsorption, the following equation can be used with the data from Figure S3 to estimate the amount of adsorbed silver on the QDs:

$$
i_{p}=\frac{n^{2} F^{2} A \Gamma^{*}}{4 R T} v
$$


where $i_{p}$ is the peak current, $n$ is the number of electrons, $F$ is the Faraday constant, $A$ is the surface area, $\Gamma^{*}$ is the surface concentration, $\mathrm{v}$ is the scan rate, $\mathrm{R}$ is the gas constant and $\mathrm{T}$ is the temperature.

As saturation conditions are employed in this case (electrodeposition using $-0.2 \mathrm{~V}$ for $60 \mathrm{~s}$ and $250 \mu \mathrm{M}$ of silver), the maximum amount of adsorbed silver that can produce the catalytic process can be estimated. The estimated value under these conditions was $1.3 \times 10^{-17}$ moles/QD. After the deposition of this amount of silver, the behaviour of the silver deposited over QDs will be similar to the silver deposited on the carbon surface.

\section{S7. QUANTUM DOTS DETECTION PROCEDURE}

Using different particle concentrations of QDs on the modified electrode, the selective stripping peak current (at $+0.45 \mathrm{~V}$ ) was found proportional to the QDs concentration. Therefore, a procedure for the electrochemical detection of QDs was developed using the selective electrodeposition of silver on these nanoparticles. The methodology is described in the main text. Deposition potential and time were optimized to obtain the highest analytical signal. No signal is observed at the stripping potential for a bare electrode, even using the more extreme deposition potential and time tested, highlighting the high selectivity of this process.

The peak current obtained was linearly proportional to the particle concentration of QDs in the solution following the equation: $\mathrm{i}(\mu \mathrm{A})=1.57[\mathrm{QDs}](\mathrm{nM})+0.007, \mathrm{R}^{2}=0.996$. The linear range obtained was from 0.5 to $25 \mathrm{nM}$, and the limit of detection, calculated as the concentration corresponding to three times the standard deviation of the estimate, was 130 pM. The calibration plot is shown in the Figure S8. With this methodology, the detection limit is significantly improved to previously reported electrochemical detection of quantum dots, even with an acid digestion (Table S2). 


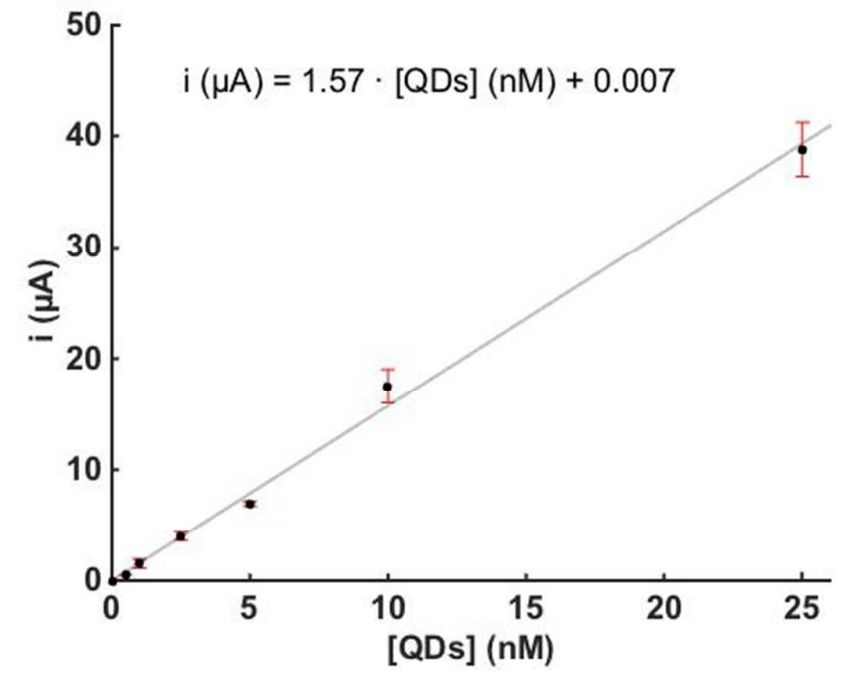

Figure S8. Calibration plot representing the peak current versus the particle concentration of the QDs solution used for the modification of the electrode surface $(0,0.5,1,2,5,10,25 \mathrm{nM})$.

\begin{tabular}{cccc} 
Reference & Linear range & Sensitivity & $\begin{array}{r}\text { Limit of } \\
\text { detection }\end{array}$ \\
\hline$[9]$ & $8-230 \mu \mathrm{M}$ & $0.05 \mu \mathrm{A} / \mu \mathrm{M}$ & $8 \mu \mathrm{M}$ \\
{$[10]$} & $5-200 \mathrm{nM}$ & $0.23 \mu \mathrm{A} / \mathrm{nM}$ & $2.6 \mathrm{nM}$ \\
This work & $0.5-25 \mathrm{nM}$ & $1.57 \mu \mathrm{A} / \mathrm{nM}$ & $130 \mathrm{pM}$ \\
\hline
\end{tabular}

Table S2. Analytical figures of merit of several electrochemical methodologies for QDs detection using screen-printed electrodes.

\section{REFERENCES}

[1] R. Barlag, F. Nyasulu, R. Starr, A Student-Made Silver-Silver Chloride Reference Electrode for the General Chemistry Laboratory: 10 min Preparation, J. Chem. Educ. 91 (2014) 766-768.

[2] E. Herrero, L.J. Buller, H.D. Abruña, Underpotential deposition at single crystal surfaces of $\mathrm{Au}, \mathrm{Pt}, \mathrm{Ag}$ and other materials, Chem. Rev. 101 (2001) 1897-930.

[3] E. Herrero, H.D. Abruña, Underpotential Deposition of Mercury on Au(111): Electrochemical Studies and Comparison with Structural Investigations, Langmuir. 13 (1997) 4446-4453.

[4] D. Hernández-Santos, M.B. González-García, A. Costa-García, Electrochemical 
determination of gold nanoparticles in colloidal solutions, Electrochim. Acta. 46 (2000) $607-615$.

[5] A. de la Escosura-Muñiz, M. Maltez-da Costa, A. Merkoçi, Controlling the electrochemical deposition of silver onto gold nanoparticles: reducing interferences and increasing the sensitivity of magnetoimmuno assays., Biosens. Bioelectron. 24 (2009) $2475-2482$.

[6] X. Mao, J. Jiang, Y. Luo, G. Shen, R. Yu, Copper-enhanced gold nanoparticle tags for electrochemical stripping detection of human IgG., Talanta. 73 (2007) 420-4.

[7] J. Ustarroz, U. Gupta, A. Hubin, S. Bals, H. Terryn, Electrodeposition of Ag nanoparticles onto carbon coated TEM grids - A direct approach to study early stages of nucleation, Electrochem. Commun. 12 (2010) 1706-1709.

[8] B. Scharifker, G. Hills, Theoretical and experimental studies of multiple nucleation, Electrochim. Acta. 28 (1983) 879-889.

[9] A. Merkoçi, L.H. Marcolino-Junior, S. Marín, O. Fatibello-Filho, S. Alegret, Detection of cadmium sulphide nanoparticles by using screen-printed electrodes and a handheld device., Nanotechnology. 18 (2007) 035502.

[10] D. Martín-Yerga, D. Bouzas-Ramos, M. Menéndez-Miranda, A.R.M. Bustos, J.R. Encinar, J.M. Costa-Fernández, et al., Voltammetric determination of size and particle concentration of Cd-based quantum dots, Electrochim. Acta. 166 (2015) 100-106. 